OPEN ACCESS

Edited by:

Richard Kremer,

McGill University, Canada

Reviewed by:

Hao Zhang,

Shanghai Sixth People's Hospital,

China

Frank Ko,

Rush University Medical Center,

United States

Marco Ponzetti,

University of L'Aquila, Italy

*Correspondence:

Lige Song

6songlige@tongji.edu.cn

${ }^{\dagger}$ These authors have contributed equally to this work

Specialty section:

This article was submitted to

Bone Research,

a section of the journal

Frontiers in Endocrinology

Received: 18 May 2020 Accepted: 28 April 2021

Published: 14 May 2021

Citation:

Wen Y, Li H, Zhang X, Liu P, Ma J, Zhang L, Zhang $K$ and Song $L$ (2021) Correlation of Osteoporosis in Patients

With Newly Diagnosed Type 2

Diabetes: A Retrospective Study in

Chinese Population.

Front. Endocrinol. 12:531904.

doi: 10.3389/fendo.2021.531904

\section{Correlation of Osteoporosis in Patients With Newly Diagnosed Type 2 Diabetes: A Retrospective Study in Chinese Population}

\author{
Yuhua Wen ${ }^{1,2 \dagger}$, Huijuan $\mathrm{Li}^{1,2 \dagger}$, Xiaoya Zhang ${ }^{1,2}$, Peipei Liu ${ }^{1}$, Jing Ma ${ }^{1}$, Liya Zhang ${ }^{1}$, \\ Keqin Zhang ${ }^{1,2}$ and Lige Song ${ }^{1,2 *}$ \\ ${ }^{1}$ Department of Endocrinology, Tongji Hospital, Tongji University School of Medicine, Shanghai, China, ${ }^{2}$ Institute of \\ Osteoporosis and Metabolic Bone Diseases, Tongji University School of Medicine, Shanghai, China
}

This study aimed to explore the risk factors attributed to osteoporosis in newly type 2 diabetes mellitus (T2DM) patients. This study aimed to recruit 244 T2DM patients and 218 non-diabetic controls. We collected demographic characteristics, medical history, bone mineral density and biomarkers including bone specific alkaline phosphatase (BALP), osteocalcin, N-terminal peptide of type I procollagen (P1NP), tartrate-resistant acid phosphatase $5 b$ (TRCAP-5b), $\beta$-Cross Laps of type I collagen-containing cross-linked C-telopeptide ( $\beta$-CTX), 25-hydroxyvitamin D, parathyroid hormone were recorded or detected. Bone mineral density (BMD) was our primary outcome. Based on the result of BMD, we divided both the control group and T2DM group into three subgroups: normal bone mass, osteopenia and osteoporosis. In control group, we found age, sex, menopausal status, BMI, P1NP, BALP, TRACP-5b, osteocalcin, and corrected serum calcium are differential among three subgroups. In T2DM group, we found age, sex, menopausal status, drinking status, BMl, $\mathrm{HbA1c}$, TRACP-5b and OC were differential among three subgroups. In T2DM and control groups, age, female, postmenopausal status, BALP, TRACP-5b and osteocalcin were positively correlated while BMI was negatively correlated with osteoporosis. In control group, $\beta$-CTX was positively correlated with osteoporosis. In T2DM group, HbA1c and corrected serum calcium concentration were positively correlated with osteoporosis. After further adjustment of age, BMI in male, TRACP-5b was positively correlated with the risk of osteoporosis in newly diagnosed T2DM. After adjusted of age, BMl and menopausal status in female, OC was positively correlated with the risk of osteoporosis in newly diagnosed T2DM and controls. In female T2DM, BALP and P1NP were positively correlated with the risk of osteoporosis. In conclusion, age, BMl and menopausal status are common risk factors for osteoporosis in diabetic and non-diabetic patients, however TRACP-5b, BALP and 
osteocalcin are special risk factors for osteoporosis in newly diagnosed T2DM patients but not non-diabetic patients, which may be applied to identify osteoporosis risk in T2DM patients, but this result needs to be proven with fracture data.

Keywords: risk assessment, type 2 diabetes mellitus, TRACP-5b, osteocalcin, osteoporosis, bone specific alkaline phosphatase

\section{INTRODUCTION}

Type 2 diabetes has affected more than 451 million individuals worldwide, and its prevalence is steadily rising following the aging of the society (1). It induces high mortality mainly due to its chronic complications, like diabetic nephropathy, retinopathy, neuropathy and cardiovascular diseases (2). Recent evidence suggests that skeleton fracture might be considered as one more chronic complication of type 2 diabetes mellitus (T2DM) (3). Fracture risk is rising following the duration of T2DM, including any fractures, spine fractures and hip fractures, but not forearm fractures (4).

Comparing to high fracture risk in type 2 diabetic patients, area bone mineral density (aBMD) based on dual energy X-ray absorptiometry (DEXA) is not differential to non-diabetes controls. Thus, fracture risk prediction based on aBMD underestimates the fracture risk of the patients with T2DM (3). Lots of previous studies have reported that for a given $\mathrm{T}$ score, T2DM patients had a higher fracture risk than those without T2DM (5). The fracture risk assessment tool (FRAX) was developed to evaluate the 10 -year probability of hip fracture and major osteoporotic fracture by the World Health Organization. However, FRAX also underestimates the fracture risk of the type 2 diabetic patients even after it included femoral neck aBMD and several clinical variables (age, sex, body mass index, use of glucocorticoids, current smoking, alcohol intake of three or more units per day, secondary osteoporosis, rheumatoid arthritis, prior fragility fracture) (5). Because of the widespread use of bone mineral density (BMD) and FRAX for predicting fracture risk in populations, lots of efforts have been put to explore the more precise way to use BMD and FRAX on fracture risk prediction in type 2 diabetic patients. The results showed that type 2 diabetic patients with femoral neck BMD T score at -2.1 in men and -1.9 in women have the same fracture risk in the non-diabetic populations with femoral neck BMD T score at -2.5 (5). If T2DM replaces RA in FRAX for evaluating fracture risk of the T2DM patients, this tool becomes more precise (6). These above results imply that T2DM patients have unique bone metabolism characteristics and risk factors that contribute to their higher fracture risk.

Many studies have been conducted to explore the mechanisms of fracture risk in type 2 diabetic patients (7). Results showed that increased risk of falls induced by hypoglycemic events (8), poor muscle strength (9), poor vision (caused by diabetic retinopathy) (10), and peripheral neuropathy (11) contributes to large amount of fractures in type 2 diabetic patients. Impaired renal function in long duration diabetic patients might interfere with vitamin $\mathrm{D}$ metabolism, which results in reduced muscle strength and impaired bone metabolism (11). Some studies find that impaired bone strength induced by bone materials imbalance and bone microstructure deterioration attributes to fracture risk in type 2 diabetic patients $(12,13)$. Moreover, some anti-diabetic drugs including TZDs, SGLT-2 inhibitors and insulin can increase fracture risk in the T2DM population (14).

However, no previous study has been conducted to explore the change of bone mineral density and bone turnover in newly diagnosed type 2 diabetic patients who are not companied with chronic diabetic complications and untreated. Thus, this study may uncover or hint unique risk factors or mechanisms of fracture risk in type 2 diabetic patients.

\section{MATERIALS AND METHODS}

\section{Study Design}

This was a retrospective study. Tongji Hospital of Tongji University School of Medicine is one of the large-scale general hospitals in Shanghai, China, which integrates medical service, education, and research. Participants were recruited from all the patients who attend the Endocrine outpatient clinic from January 2014 to February 2018.

\section{Participants}

812 individuals with newly-onset type 2 diabetes and 759 individuals without diabetes, who do not meet the exclusion criteria, were included in this study. Exclusion criteria for patient selection were as follows: 1) the history of fragility fractures (fractures influence bone turnover markers in the 6 months after fractures happen); 2) with secondary osteoporosis; 3) exposed to medicine associated with osteoporosis; 4) with malignant tumors; 5) with autoimmune diseases; 6) treated by antidiabetic drugs.

244 newly diagnosed type 2 diabetes patients and 218 nondiabetic individuals were enrolled. Clinical characteristics, fracture history, whole blood cell analysis, biochemical indicator, electrolytes, bone turnover markers were recorded at the first visit and bone mineral density (BMD) was assessed three-month after the first visit. Statistical analysis was used to explore the risk factors attributed to osteoporosis in newly type 2 diabetic patients.

The diagnosis of type 2 diabetes depends on the criteria of WHO (1999) (15). The individuals who were included in this study should also have been tested for liver function, renal function, fasting plasma glucose (FPG), glycosylated hemoglobin (hemoglobin A1c, HbA1c), fasting C-peptide (CPS), serum electrolyte indices, thyroid function, calcium 
(Ca), phosphorus (P), parathyroid hormone (PTH), 25hydroxyvitamin D $(25(\mathrm{OH}) \mathrm{D})$ and bone turnover markers $(\mathrm{N}$ terminal peptide of type I procollagen (P1NP), $\beta$-Cross Laps of type I collagen-containing cross-linked C-telopeptide ( $\beta$-CTX), bone specific alkaline phosphatase (BALP), tartrate-resistant acid phosphatase 5b(TRACP-5b), osteocalcin (OC) at the first time of clinical visit. Bone mineral density (BMD) at three sites (lumbar, femur neck, and total hip) were detected by dual-energy X-ray absorptiometry (DXA) scans 3 months after the first time of clinical visit.

After applying these exclusion and inclusion criteria, 244 newly diagnosed type 2 diabetes mellitus (DM) and 218 nondiabetic mellitus (Non-DM) individuals were included in this study. The Ethics Committee approved this study of Tongji Hospital of Tongji University School of Medicine and all the participants signed the informed consents. Based on the BMD from DEXA, we divided participants into three subgroups: normal, osteopenia, and osteoporosis according to WHO osteoporosis diagnostic criteria (16). Briefly, the lowest $\mathrm{T}$ scores in the three sites were used to classify the individuals into three subgroups: normal ( $\mathrm{T}$ score $>-1$ ), osteopenia (T score between -1 and -2.5 ), and osteoporosis ( $\mathrm{T}$ score $<-2.5$ ).

\section{Data Collection}

The general characteristics of the enrolled individuals were recorded during the first time of clinical visit, including age, gender, menopause status, drinking, smoking, body weight, and height. The smoking status depends on whether the individual is currently smoking. The alcohol consumption depended on whether the patient takes three or more units of alcohol daily (one unit of alcohol means $8 \mathrm{~g}$ of alcohol). Liver function, renal function, FPG, and electrolytes were detected by Advia-1650 automatic chemistry analyzer (Bayer Diagnostics, Tarletown, NY, USA). CPS was measured by chemical luminescence (Siemens CENTAUR XP Chemical Glow Immunoassay Analyzer). P1NP, OC, $\beta$-CTX, 25(OH)D, PTH were measured by electrochemiluminescence assay (Roche Diagnostics). BALP and TRACP-5b were measured by enzyme immunoassay (IDS Ltd). HbAlc was measured by high-performance liquid chromatography. Corrected $\mathrm{Ca}(\mathrm{mmol} / \mathrm{L})$ was calculated as the formula: $\mathrm{Ca}(\mathrm{mmol} / \mathrm{L})+0.02 \times[40$-albumin $(\mathrm{g} / \mathrm{L})]$. Bone mineral density (BMD) at lumbar, femur neck, and total hip were detected by dual-energy X-ray absorptiometry (DXA) scans (DXA, HOLOGIC Discovery; coefficient of variation $<1 \%$ ).

\section{Statistical Analysis}

The percentage was used to describe the categorical variables. Continuous variables in normal distribution were expressed as mean \pm SD. Median and percentages were used for continuous variables that were not in the normal distribution. Chi-squared tests analyzed comparisons between the categorical variables. The analysis of variance (ANOVA) was applied in continuous variables that were in the normal distribution. Kruskal-Wallis test was used in continuous variables that were not in the normal distribution. The logistic regression analysis without adjustment was performed including potential indicators. Then the data has stratified the cohorts by gender. In the male model, we adjusted
BMI and age. And, in the female model, we adjusted age, menopause status, and BMI. A P-value $<0.05$ was considered statistically significant. All statistical calculations were performed using the Statistical Package for the Social Sciences software for Windows version 20.0 (IBM, Armonk, NY, USA).

\section{RESULTS}

Comparing to type 2 diabetic individuals, the proportion of smoking and drinking in non-diabetic individuals was lower (6.9\% vs $21.7 \%$ and $3.2 \%$ vs $10.7 \%$ ) and their BMI was also lower $\left(25.28 \pm 3.87 \mathrm{~kg} / \mathrm{m}^{2}\right.$ vs $\left.23.39 \pm 3.98 \mathrm{~kg} / \mathrm{m}^{2}\right)$. Serum $25-$ hydroxyvitamin $\mathrm{D}$ level in diabetic patients was lower when compared to the non-diabetic individuals (31.68 vs $38.91 \mathrm{nmol} / \mathrm{l}$ ) (Supplementary Table 1).

In the control group, we found age $(\mathrm{P}$-value $<0.001)$, gender $(\mathrm{P}$ value $=0.011)$, postmenopausal status $(\mathrm{P}$-value $<0.001), \mathrm{BMI}(\mathrm{P}$ value $<0.001)$, correlated $\mathrm{Ca}(\mathrm{P}$-value $=0.034), \mathrm{P} 1 \mathrm{NP}(\mathrm{P}$-value $=$ 0.002), BALP (P-value $=0.009)$, TRACP-5b $(\mathrm{P}$-value $=0.015)$, OC (P-value $<0.001)$ are differential among three subgroups (Table 1). And there is weak or no evidence against the null hypothesis that current drinking, current smoking, FPG, HbAlc, Ca, P, PTH, 25 $(\mathrm{OH}) \mathrm{D}$ were the same in three subgroups. In the type 2 diabetic group, older age, female, postmenopausal status, and lower BMI were related to a higher possibility of osteoporosis. Current smoking had no relationship with the bone mass decline in type 2 diabetic groups, but the rate of current drinking is lower in the osteoporosis patients in type 2 diabetic group but not in the non-diabetic group (Table 1).

According to glucose level, FPG had no difference between normal, osteopenia, and osteoporosis subgroups in both nondiabetic and type 2 diabetic groups, but higher HbAlc was related to lower BMD in the type 2 diabetic group (Table 1). Total calcium level (normalized by serum albumin concentration) is positively related to the bone mass decline in the non-diabetic group but not in the diabetic group, however, the level of calcium-regulating hormones, PTH and 25(OH)D, had no difference between normal, osteopenia and osteoporosis subgroups in both type 2 diabetic and non-diabetic groups (Table 1). According to bone turnover markers, levels of TRACP-5b and OC were higher in the osteoporotic group comparing to osteopenia and normal groups in both type 2 diabetic and non-diabetic populations, and the levels of $\mathrm{P} 1 \mathrm{NP}$ and BALP had the same trend in the non-diabetic group but not in the diabetic group. $\beta$-CTX level showed no difference between the three subgroups in both diabetic and non-diabetic populations (Table 1 and Figure 1).

In the control group, logistic regression analysis showed that age, postmenopausal status, correlated $\mathrm{Ca}, \beta$-CTX, BALP TRACP-5b, and OC could increase the risk of osteoporosis while BMI could decrease the risk (Table 2). Interestingly, current drinking was negatively related to the risk of osteoporosis in the diabetic group but not in the non-diabetic group (Table 2). In diabetic groups, HbA1c, BALP, TRACP-5b, and $\mathrm{OC}$ levels could increase the risk of osteoporosis $(\mathrm{P}<0.05)$. P1NP neither increases nor decreases the risk of osteoporosis in diabetic and non-diabetic groups (Table 2). 
TABLE 1 | Baseline characteristics of patients with T2DM and non-diabetic controls.

\begin{tabular}{|c|c|c|c|c|c|c|c|c|}
\hline \multirow[t]{2}{*}{ Variables } & \multicolumn{4}{|c|}{ Non-DM } & \multicolumn{4}{|c|}{ DM } \\
\hline & Normal $(\mathrm{N}=23)$ & $\begin{array}{l}\text { Osteopenia } \\
\qquad(N=78)\end{array}$ & $\begin{array}{l}\text { Osteoporosis } \\
(N=117)\end{array}$ & P-value & $\begin{array}{l}\text { Normal } \\
(\mathrm{N}=67)\end{array}$ & $\begin{array}{l}\text { Osteopenia } \\
(N=118)\end{array}$ & $\begin{array}{l}\text { Osteoporosis } \\
\qquad(\mathrm{N}=59)\end{array}$ & P-value \\
\hline Age (years) & $56.44 \pm 15.86$ & $64.94 \pm 12.48$ & $69.98 \pm 12.16$ & $\begin{array}{c}P \\
<0.001\end{array}$ & $55.00 \pm 13.46$ & $59.29 \pm 11.14$ & $65.73 \pm 10.08$ & $\begin{array}{c}P \\
<0.001\end{array}$ \\
\hline Gender (Male, \%) & $9(39.1 \%)$ & $21(26.9 \%)$ & $17(14.5 \%)$ & $\begin{array}{c}P= \\
0.011\end{array}$ & $37(55.2 \%)$ & $71(60.2 \%)$ & $21(35.6 \%)$ & $\begin{array}{c}P= \\
0.008\end{array}$ \\
\hline Postmenopausal (\%) & 9 (39.1\%) & $51(65.4 \%)$ & $98(83.8 \%)$ & $\begin{array}{c}P \\
<0.001\end{array}$ & 22 (32.8\%) & $44(37.3 \%)$ & $37(62.7 \%)$ & $\begin{array}{c}P= \\
0.001\end{array}$ \\
\hline Current smoking (\%) & $2(8.7 \%)$ & $4(5.1 \%)$ & $9(7.7 \%)$ & $\begin{array}{c}P= \\
0.736\end{array}$ & 17 (25.4\%) & $29(24.6 \%)$ & $7(11.9 \%)$ & $\begin{array}{c}P= \\
0.101\end{array}$ \\
\hline Current drinking (\%) & $0(0.0 \%)$ & $2(2.6 \%)$ & $5(4.3 \%)$ & $\begin{array}{c}P= \\
0.745\end{array}$ & $9(13.4 \%)$ & $16(13.6 \%)$ & $1(1.7 \%)$ & $\begin{array}{c}P= \\
0.038\end{array}$ \\
\hline $\mathrm{BMl}(\mathrm{kg} / \mathrm{m} 2)$ & $26.34 \pm 5.22$ & $23.81 \pm 3.36$ & $22.54 \pm 3.79$ & $\begin{array}{c}P \\
<0.001\end{array}$ & $27.22 \pm 4.23$ & $25.26 \pm 3.49$ & $23.11 \pm 2.99$ & $\begin{array}{c}P \\
<0.001\end{array}$ \\
\hline $\mathrm{FPG}(\mathrm{mmol} / \mathrm{L})$ & $4.93(4.61-5.35)$ & 5.07 (4.72-5.54) & 4.95 (4.71-5.39) & $\begin{array}{c}P= \\
0.361\end{array}$ & $9.39(7.10-11.40)$ & 9.39 (7.47-12.29) & $9.43(7.86-12.52)$ & $\begin{array}{c}P= \\
0.448\end{array}$ \\
\hline HbA1c (\%) & $5.71 \pm 0.31$ & $5.77 \pm 0.34$ & $5.74 \pm 0.36$ & $\begin{array}{c}P= \\
0.680\end{array}$ & $10.27 \pm 2.54$ & $10.78 \pm 2.47$ & $11.58 \pm 2.10$ & $\begin{array}{c}P= \\
0.010\end{array}$ \\
\hline $\mathrm{Ca}(\mathrm{mmol} / \mathrm{L})$ & $2.20 \pm 0.11$ & $2.21 \pm 0.11$ & $2.23 \pm 0.14$ & $\begin{array}{c}P= \\
0.491\end{array}$ & $2.22 \pm 0.10$ & $2.21 \pm 0.11$ & $2.23 \pm 0.14$ & $\begin{array}{c}P= \\
0.454\end{array}$ \\
\hline $\begin{array}{l}\text { Correlated Ca } \\
(\mathrm{mmol} / \mathrm{L})\end{array}$ & $2.22(2.14-2.28)$ & $2.23(2.17-2.28)$ & $2.25(2.21-2.31)$ & $\begin{array}{c}P= \\
0.034\end{array}$ & $2.23(2.17-2.28)$ & $2.22(2.18-2.28)$ & 2.25 (2.20-2.30) & $\begin{array}{c}P= \\
0.125\end{array}$ \\
\hline $\mathrm{P}(\mathrm{mmol} / \mathrm{L})$ & $1.21 \pm 0.22$ & $1.19 \pm 0.17$ & $1.23 \pm 0.18$ & $\begin{array}{c}P= \\
0.355\end{array}$ & $1.24 \pm 0.16$ & $1.21 \pm 0.20$ & $1.21 \pm 0.23$ & $\begin{array}{c}P= \\
0.561\end{array}$ \\
\hline PTH (pg/ml) & $\begin{array}{c}46.34(39.2- \\
60.11)\end{array}$ & $\begin{array}{c}44.75(32.85- \\
57.11)\end{array}$ & $\begin{array}{c}45.3(36.41- \\
56.51)\end{array}$ & $\begin{array}{c}P= \\
0.583\end{array}$ & $\begin{array}{c}39.00(31.78- \\
49.14)\end{array}$ & $\begin{array}{c}39.00(32.47- \\
48.44)\end{array}$ & $\begin{array}{c}39.00(29.40- \\
48.87)\end{array}$ & $\begin{array}{c}P= \\
0.574\end{array}$ \\
\hline 25(OH)D (nmol/L) & $\begin{array}{c}41.46(22.87- \\
55.63)\end{array}$ & $\begin{array}{c}38.9(28.65- \\
45.27)\end{array}$ & $\begin{array}{c}37.91(27.58- \\
48.67)\end{array}$ & $\begin{array}{c}P= \\
0.591\end{array}$ & $\begin{array}{c}33.73(25.43- \\
42.78)\end{array}$ & $\begin{array}{c}31.68(24.82- \\
43.62)\end{array}$ & $\begin{array}{c}30.20(23.67- \\
39.24)\end{array}$ & $\begin{array}{c}P= \\
0.239\end{array}$ \\
\hline $\mathrm{P} 1 \mathrm{NP}$ (ng/mL) & $\begin{array}{c}41.00(27.10- \\
48.10)\end{array}$ & $\begin{array}{c}45.55(33.53- \\
61.43)\end{array}$ & $\begin{array}{c}55.40(40.30- \\
68.12)\end{array}$ & $\begin{array}{c}P= \\
0.002\end{array}$ & $\begin{array}{c}38.20(32.50- \\
49.41)\end{array}$ & $\begin{array}{c}38.20(30.54- \\
47.22)\end{array}$ & $\begin{array}{c}38.20(33.40- \\
56.10)\end{array}$ & $\begin{array}{c}P= \\
0.269\end{array}$ \\
\hline CTX (ng/mL) & $0.36(0.25-0.56)$ & $0.45(0.23-0.58)$ & $0.49(0.29-0.69)$ & $\begin{array}{c}P= \\
0.072\end{array}$ & $0.38(0.24-0.55)$ & $0.38(0.27-0.47)$ & $0.44(0.32-0.71)$ & $\begin{array}{c}P= \\
0.056\end{array}$ \\
\hline BALP ( $\mu g / L)$ & $\begin{array}{c}11.80(9.40- \\
15.10)\end{array}$ & $\begin{array}{c}14.73(11.13- \\
20.15)\end{array}$ & $\begin{array}{c}15.40(12.65- \\
20.10)\end{array}$ & $\begin{array}{c}P= \\
0.009\end{array}$ & $\begin{array}{c}18.10(13.50- \\
20.20)\end{array}$ & $\begin{array}{c}18.30(15.35- \\
22.13)\end{array}$ & $\begin{array}{c}18.30(15.70- \\
26.20)\end{array}$ & $\begin{array}{c}P= \\
0.083\end{array}$ \\
\hline TRACP-5b (U/L) & $1.82 \pm 0.52$ & $2.26 \pm 0.72$ & $2.28 \pm 0.73$ & $\begin{array}{c}P= \\
0.015\end{array}$ & $2.18 \pm 0.61$ & $2.32 \pm 0.59$ & $2.57 \pm 0.74$ & $\begin{array}{c}P= \\
0.003\end{array}$ \\
\hline $\mathrm{OC}(\mathrm{ng} / \mathrm{mL})$ & $\begin{array}{c}15.26(11.84- \\
19.68)\end{array}$ & $\begin{array}{c}19.20(14.55- \\
22.93)\end{array}$ & $\begin{array}{c}21.68(15.68- \\
29.27)\end{array}$ & $\begin{array}{c}P \\
<0.001\end{array}$ & $\begin{array}{c}12.83(11.01- \\
15.44)\end{array}$ & $\begin{array}{c}12.83(10.08- \\
14.85)\end{array}$ & $\begin{array}{c}15.19(12.71- \\
19.57)\end{array}$ & $\begin{array}{c}P= \\
0.001\end{array}$ \\
\hline
\end{tabular}

${ }^{*} P<0.05$. Values are shown as median (p25-p75), means $\pm S D$ or number (percentage).

To clarify the relationship between different bone turnover markers and $\mathrm{HbAlc}$ with the occurrence of osteoporosis, we built four models: male with T2DM, male without T2DM, female with T2DM, and female without T2DM. We adjusted age and BMI in males with T2DM, males without T2DM model, and adjusted age, BMI, and menopausal status in the female with T2DM and female without T2DM. For males, the results showed TRACP-5b and osteoporosis are potential risk factors of osteoporosis in the diabetic model, but not in the non-diabetic model. For women, we found the OC level was a potential risk factor for osteoporosis in the diabetic and non-diabetic models. P1NP and BALP were potential risk factors of osteoporosis only in the female with T2DM model but not in female without T2DM model (Table 3).

\section{DISCUSSION}

Age and menopause are the major determinants for the risk of osteoporosis and its related fragile fractures. In the Chinese population, recently published data from a multicenter, largescale study showed that osteoporosis increases prominently as age increases in both men and women after 55 based on BMD of lumbar spine femoral neck total femur detected by DEXA (17). In worldwide, the number of estimated individuals with osteoporosis and its related fractures by 2020 will steadily increase following the aging of the whole society. More and more efforts have been put into preventing osteoporotic fractures (18). The prevalence of osteoporosis in men (4.3\%) is lower than in women (15.4\%) according to estimates of the number of US residents in 2010 (19). For women, after menopause, their bone mass decreases about $12-20 \%$ in the first five years (20). Thus, lower peak bone mass and postmenopausal estrogen deficiency induce higher fracture risk and earlier occurrence of fragile fractures in women comparing to men (21). Data have shown that compared with men, osteoporosis is four times higher in women aged 50 years and older, and the incidence of osteopenia is two times higher $(22,23)$. The result in Table 2 showed that the current drinking was negatively related to the risk of 

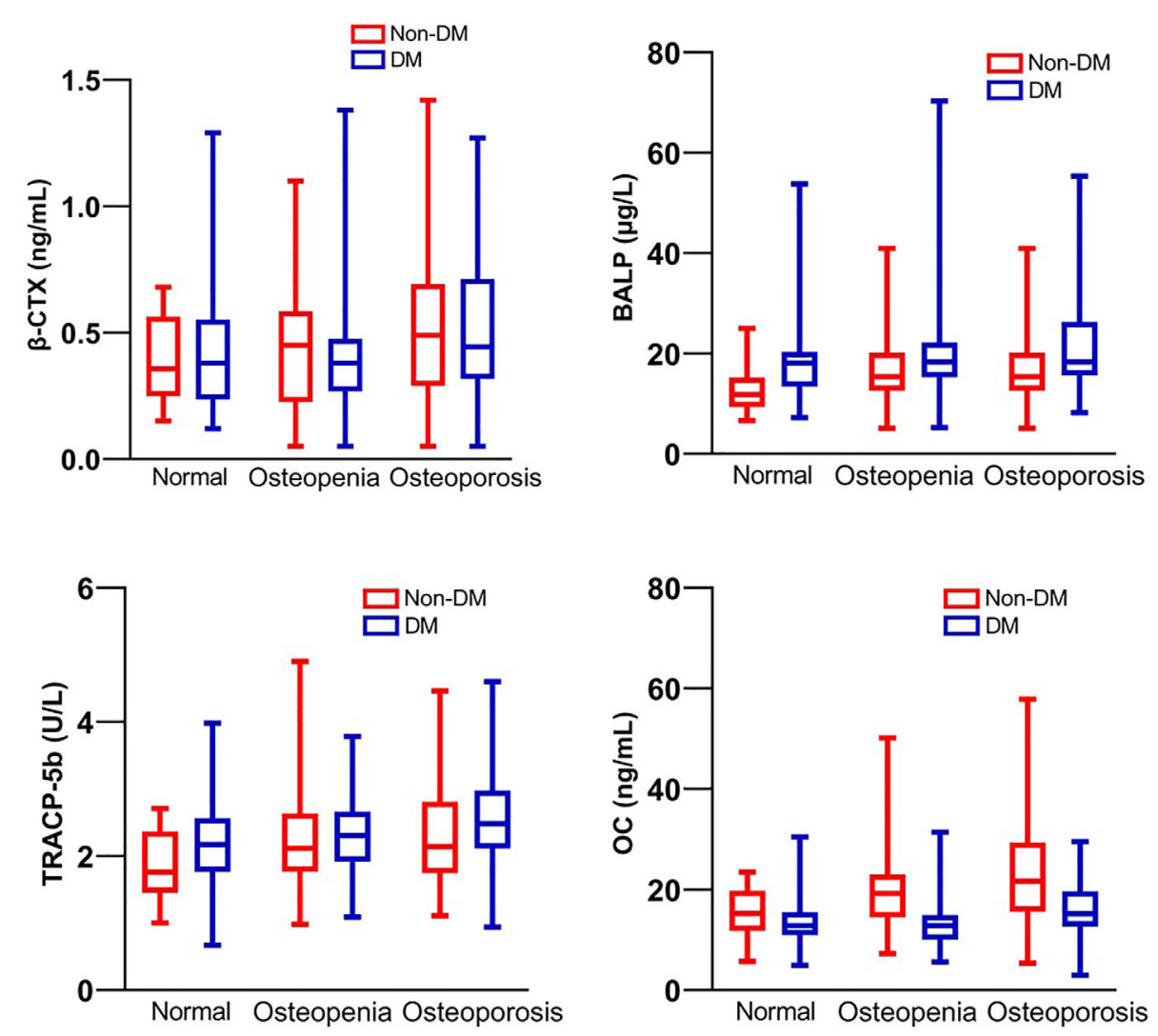

FIGURE 1 | Bone turnover markers $\beta$-CTX, BALP, TRACP-5b and OC of patients with T2DM and non-diabetic controls.

osteoporosis in the diabetic group. The result in Table 3 showed that after adjusted by age, BMI, and menopausal status, there is weak evidence against current drinking is neither a risk factor nor a protective factor. This result contradicts to some early studies. We believe the explanation is patients who take alcohol are more likely to have higher BMI. According to some studies, low BMI is an indicator for osteoporosis and its related fractures, and the study conducted in United Stated has shown that BMI $\left(<28 \mathrm{~kg} / \mathrm{m}^{2}\right)$ in White women should be put into a priority for BMD screening (24). The popularity of BMI on evaluating fracture risk base on its easy way to measure, but it cannot distinguish between fat mass and lean mass. Studies have

TABLE 2 | The relationship between the indicators with the risk of osteoporosis in diabetes and non-diabetics.

\begin{tabular}{|c|c|c|c|c|c|c|}
\hline \multirow[t]{2}{*}{ Variables } & \multicolumn{3}{|c|}{ Non-DM } & \multicolumn{3}{|c|}{ DM } \\
\hline & Odds ratio & $95 \% \mathrm{Cl}$ & P-value & Odds ratio & $95 \% \mathrm{Cl}$ & P-value \\
\hline Age (years) & 1.050 & $1.028-1.072$ & $<0.001^{\star}$ & 1.053 & $1.032-1.076$ & $<0.001^{*}$ \\
\hline Gender (Male, \%) & 0.395 & $0.213-0.734$ & $0.003^{\star}$ & 0.659 & $0.487-0.892$ & $0.007^{\star}$ \\
\hline Postmenopausal (\%) & 3.877 & $2.150-6.991$ & $<0.001^{*}$ & 2.292 & $1.404-3.743$ & $0.001^{*}$ \\
\hline Current drinking (\%) & 2.374 & $0.445-12.660$ & 0.311 & 0.519 & $0.325-0.828$ & $0.006^{\star}$ \\
\hline BMI $\left(\mathrm{kg} / \mathrm{m}^{2}\right)$ & 0.862 & $0.805-0.924$ & $<0.001^{\star}$ & 0.813 & $0.758-0.871$ & $<0.001^{*}$ \\
\hline $\mathrm{HbA1c}(\%)$ & 0.925 & $0.442-1.937$ & 0.837 & 1.160 & $1.051-1.281$ & $0.003^{*}$ \\
\hline Correlated $\mathrm{Ca}(\mathrm{mmol} / \mathrm{L})$ & 3.914 & $0.943-16.248$ & 0.06 & 12.587 & $1.024-154.788$ & $0.048^{*}$ \\
\hline PTH (pg/ml) & 1.004 & 0.992-1.017 & 0.51 & 0.996 & $0.982-1.011$ & 0.582 \\
\hline 25(OH)D (nmol/L) & 1.003 & $0.988-1.018$ & 0.705 & 0.993 & $0.977-1.009$ & 0.381 \\
\hline P1NP (ng/ml) & 1.003 & 0.995-1.011 & 0.397 & 1.011 & $0.997-1.025$ & 0.121 \\
\hline$\beta-C T X(n g / m l)$ & 3.721 & $1.297-10.674$ & $0.015^{\star}$ & 2.045 & $0.776-5.384$ & 0.148 \\
\hline BALP $(\mu \mathrm{g} / L)$ & 1.021 & $1.001-1.042$ & $0.043^{\star}$ & 1.031 & $1.003-1.060$ & $0.029^{\star}$ \\
\hline TRACP-5b (U/L) & 1.324 & $1.072-1.635$ & $0.009^{\star}$ & 1.932 & $1.324-2.819$ & $0.001^{*}$ \\
\hline $\mathrm{OC}(\mathrm{ng} / \mathrm{ml})$ & 1.040 & $1.021-1.059$ & $<0.001^{\star}$ & 1.066 & $1.016-1.119$ & $0.009^{\star}$ \\
\hline
\end{tabular}

${ }^{\star} P<0.05$. Logistic regression analysis without adjustment. 
TABLE 3 | The relationship between the indicators with the risk of osteoporosis in diabetes and non-diabetics with gender stratification and adjustment.

\begin{tabular}{|c|c|c|c|c|c|c|c|c|c|c|c|c|}
\hline \multirow[t]{3}{*}{ Variables } & \multicolumn{6}{|c|}{ Male } & \multicolumn{6}{|c|}{ Female } \\
\hline & \multicolumn{3}{|c|}{ Non-DM } & \multicolumn{3}{|c|}{ DM } & \multicolumn{3}{|c|}{ Non-DM } & \multicolumn{3}{|c|}{ DM } \\
\hline & $\begin{array}{l}\text { Odds } \\
\text { ratio }\end{array}$ & $95 \% \mathrm{Cl}$ & $\begin{array}{c}\text { P- } \\
\text { value }\end{array}$ & $\begin{array}{l}\text { Odds } \\
\text { ratio }\end{array}$ & $95 \% \mathrm{Cl}$ & $\begin{array}{c}\text { P- } \\
\text { value }\end{array}$ & $\begin{array}{l}\text { Odds } \\
\text { ratio }\end{array}$ & $95 \% \mathrm{Cl}$ & $\begin{array}{c}\text { P- } \\
\text { value }\end{array}$ & $\begin{array}{l}\text { Odds } \\
\text { ratio }\end{array}$ & $95 \% \mathrm{Cl}$ & $\begin{array}{c}\mathrm{P} \text { - } \\
\text { value }\end{array}$ \\
\hline Current drinking (\%) & 5.855 & $\begin{array}{c}0.886- \\
38.68\end{array}$ & 0.067 & 0.435 & $0.182-1.041$ & 0.061 & & & & & & \\
\hline HbA1c (\%) & 0.509 & $\begin{array}{c}0.111- \\
2.347\end{array}$ & 0.387 & 1.085 & $0.943-1.249$ & 0.255 & 1.442 & $\begin{array}{c}0.519- \\
4.004\end{array}$ & 0.482 & 1.097 & 0.933-1.29 & 0.262 \\
\hline $\begin{array}{l}\text { Correlated Ca } \\
(\mathrm{mmol} / \mathrm{L})\end{array}$ & 4.92 & $\begin{array}{l}0.351- \\
68.937\end{array}$ & 0.237 & 6.773 & $\begin{array}{c}0.119- \\
385.677\end{array}$ & 0.354 & 3.038 & $\begin{array}{l}0.545- \\
16.942\end{array}$ & 0.205 & 15.066 & $\begin{array}{c}0.489- \\
464.619\end{array}$ & 0.121 \\
\hline PTH (pg/ml) & 0.991 & $\begin{array}{c}0.953- \\
1.031\end{array}$ & 0.651 & 0.985 & $0.963-1.009$ & 0.22 & 1.005 & $0.99-1.02$ & 0.511 & 1.006 & $0.984-1.028$ & 0.609 \\
\hline 25(OH)D (nmol/L) & 0.963 & $\begin{array}{c}0.924- \\
1.005\end{array}$ & 0.082 & 0.99 & $0.968-1.013$ & 0.376 & 1.013 & $\begin{array}{c}0.993- \\
1.033\end{array}$ & 0.203 & 0.989 & $0.961-1.018$ & 0.456 \\
\hline P1NP (ng/ml) & 1.025 & $0.992-1.06$ & 0.138 & 1.009 & $0.984-1.035$ & 0.47 & 0.999 & $\begin{array}{c}0.992- \\
1.005\end{array}$ & 0.688 & 1.026 & $1.005-1.047$ & $0.014^{*}$ \\
\hline$\beta-C T X(n g / m l)$ & 0.412 & 0.02-8.343 & 0.563 & 2.383 & $\begin{array}{l}0.445- \\
12.756\end{array}$ & 0.31 & 3.177 & $\begin{array}{l}0.869- \\
11.611\end{array}$ & 0.081 & 1.791 & $0.45-7.117$ & 0.408 \\
\hline BALP $(\mu g / L)$ & 1.03 & $\begin{array}{c}0.957- \\
1.109\end{array}$ & 0.426 & 1.02 & $0.972-1.071$ & 0.419 & 1.049 & $1-1.1$ & 0.052 & 1.053 & $1.013-1.095$ & $0.009^{\star}$ \\
\hline TRACP-5b (U/L) & 2.095 & $\begin{array}{c}0.917- \\
4.787\end{array}$ & 0.079 & 2.204 & $1.215-3.995$ & $0.009^{*}$ & 1.161 & $\begin{array}{c}0.734- \\
1.838\end{array}$ & 0.524 & 1.446 & $0.829-2.522$ & 0.194 \\
\hline OC (ng/ml) & 1.079 & $\begin{array}{c}0.985- \\
1.184\end{array}$ & 0.103 & 1.018 & $0.941-1.103$ & 0.65 & 1.058 & $\begin{array}{c}1.016- \\
1.101\end{array}$ & $0.006^{*}$ & 1.113 & $1.034-1.198$ & $0.004^{*}$ \\
\hline
\end{tabular}

${ }^{*} P<0.05$. Logistic regression analysis with adjustment of age and BMI in male and adjustment of age, BMI, and menopausal status in female.

shown that fat mass is inversely, but lean mass is positively related to bone mass (25), thus BMI is an important indicator found in other studies.

Type 2 diabetes has been recognized as an independent risk for fragile fractures $(5,26)$. The high fracture risk in T2DM patients can be induced by hypoglycemia, muscle weakness and the chronic complications (such as retinopathy, neuropathy, and neuropathy) which usually happen in the patient with longer duration of T2DM (27). However, hyperglycemia should always be kept in mind because it plays a vital role during the impaired bone metabolism in T2DM patients, leading to reduced bone strength (7). In this study, the risk of osteoporosis increased following $\mathrm{HbAlc}$ level in newly diagnosed T2DM, and this result implies elevated glucose level can damage bone metabolism even in the early stage of T2DM. Hyperglycemia and its associated hyperosmolarity also suppress the expression of genes associated with osteoblast maturation (28). Hyperglycemia causes calcium homeostasis imbalance by inhibiting the bone formation and accelerating bone resorption. The clinical manifestation is a decrease in primary and secondary sponge trabecular bone mass. Increased osteoblast apoptosis induced by high glucose has been demonstrated. Hyperglycemia may inhibit osteogenic transdifferentiation and bone resorptionrelated gene matrices, including metalloproteinase (MMP) 9 and carbonic anhydrase II (CAII), increased expression levels. At the same time, osteogenesis-related genes Runx2 and alkaline phosphatase (ALP) expression levels decreased (29). Osteogenesis was inhibited when the mesenchymal progenitor cells were exposed to high glucose by activating the Notch2 signaling pathway (30).

AGEs, imbalanced inflammatory cytokines, impaired incretin system, and bone marrow adiposity can also influence the bone metabolism of the T2DM patients. Advanced glycation end products (AGEs) are important causes of inflammatory events that trigger diabetes and its complications (31). Our study found the TRACP-5b is significantly associated with osteoporosis in DM patients while it is not in healthy cohorts. In previous research, the numbers and capacity of osteoclasts and the levels of TRACP-5b were substantially increased in streptozotocin-induced diabetic rats compared with controls (32). The results of the cell experiment used osteoblast-like cells presented evidence that advanced glycation endproducts could increase cellular alkaline phosphatase activity at first and regulate osteoblast proliferation and differentiation (33). In primary human osteoblast cultures and osteocyte-like MLO-Y4-A2 cells, by activating the AGE-RAGE pathway (RAGE mRNA upregulation), $\mathrm{HG}$ and AGEs can suppress bone formation by inducing enhanced sclerostin expression in osteocytes. Moreover, AGEs suppressed bone resorption by decreasing RANKL expression and enhanced osteoclastogenesis. Besides, AGEs may cause bone deterioration by impaired matrix mineralization (downregulation of alkaline phosphatase and osteocalcin mRNA) $(34,35)$. In mouse stromal ST2 cells, the findings indicated that AGE2 and AGE3 partially inhibited the osteoblastic differentiation of stromal cells by binding to RAGE and decreasing osterix expression. The AGEs not only inhibited cell growth but also increased cell apoptosis. They also suggest that AGE3 increasing TGF-beta expression and secretion, as in diabetes-related bone disorder, the TGF-beta harms bone quality $(36,37)$.

In short, the accumulation of AGEs and these processes may cause bone matrix damage, bone strength impairment, and low bone turnover in DM (38). Low levels of inflammatory cytokines have a specific protective effect on islet $\beta$ cells, and the level of 
inflammatory cytokines is a risk factor for osteoporosis in diabetic patients (39). Generally, IL-1 and tumor necrosis factor- $\alpha$ (TNF- $\alpha$ ) not only induce the expression of RANKL to promote the osteoclastogenic process, but they also affect osteoclast activity by executing an anti-apoptotic effect (40). It was reported that serum levels of CRP, as a vital inflammation marker, could independently predict low levels of BMD (41). Low concentration of TNF- $\alpha$ or suppression of TNF- $\alpha$ by TNF soluble binding protein or an anti-TNF- $\alpha$ seems to have a role in suppressing bone resorption by decreasing osteoclast formation induced by the RANKL (42). The incretin system includes glucagon-like peptide-1 (GLP-1) and glucose-dependent insulinotropic polypeptide (GIP). Both of them may promote beta-cell proliferation, prevent apoptosis, and are essential for blood glucose regulation (43). GIP can affect bone health by stimulating osteoblast proliferation and enhancing the expression of collagen type I and the activity of alkaline phosphatase (44). GIP can affect bone health through stimulating osteoblast proliferation, as well as enhancing the expression of collagen type I and the activity of alkaline phosphatase.

Additionally, GIP restrains osteoclast activity by cyclic adenosine monophosphate (cAMP) (45). The GLP-1 may have a positive link with bone strength, as the studies indicated that it promoted osteogenic differentiation (46). In terms of the correlation between bone marrow adiposity and bone health, it has been reported that there is a strong linkage between them. Furthermore, some previous studies prove that bone marrow fat fraction (BMFF) had a negative link with bone mineral density (47). Sheu suggested that compared to the 118 participants without diabetes, 38 older diabetic participants' vertebral marrow adiposity was higher in the Osteoporotic Fractures in Men (MrOS) study (48). Besides, plenty of studies indicated that marrow adiposity is higher in osteopenic compared to healthy, and in osteoporotic compared to osteopenic people (49).

We are aware of the limitations of our study. The first limitation was that we did not collect the abdominal circumference and hip circumference data, which are important for assessing the relationship between obesity and osteopenia in T2DM. The second limitation was that our study was limited to the Chinese population. There may be differences in bone metabolism between eastern and western populations. The predicted fracture probability of women in mainland China is much lower than that of the United Kingdom when the10-year risk of hip fracture was estimated (50). Another result that needed to be cautious was that we did not find the difference between $\beta$-CTX and osteoporosis in different groups. We have known that $\beta$-CTX is the most sensitive and stable bone turnover marker. It may cause by the different duration of diabetes or diabetes drugs. We think $\beta$-CTX can predict fracture in our follow-up prospective study.

\section{REFERENCES}

1. Cho NH, Shaw JE, Karuranga S, Huang Y, da Rocha Fernandes JD, Ohlrogge AW, et al. Idf Diabetes Atlas: Global Estimates of Diabetes Prevalence for 2017 and Projections for 2045. Diabetes Res Clin Pract (2018) 138:271-81. doi: 10.1016/j.diabres.2018.02.023
In summary, age, BMI, and menopausal status are common risk factors for osteoporosis in diabetic and non-diabetic patients. However, TRACP-5b, BALP, and osteocalcin are particular risk factors for osteoporosis in newly diagnosed T2DM patients but not non-diabetic patients. The conclusion of this study may be applied to identify osteoporosis risk in Chinese T2DM patients, but this result needs to be proven with a larger population and fracture data.

\section{DATA AVAILABILITY STATEMENT}

The original contributions presented in the study are included in the article/Supplementary Material. Further inquiries can be directed to the corresponding author.

\section{ETHICS STATEMENT}

This study has been approved by the Ethics Committee of Tongji Hospital, Tongji University School of Medicine (KYSB-2018-136).

\section{AUTHOR CONTRIBUTIONS}

Conception and design: YW, HL, KZ, and LS. Administrative support: KZ and LS. Provision of study materials or patients: YW, HL, XZ, PL, JM, LZ, KZ, and LS. Collection and assembly of data: YW, HL, XZ, PL, JM, LZ, KZ, and LS. Data analysis and interpretation: YW, HL, XZ, PL, JM, LZ, KZ, and LS. Manuscript writing: all authors. All authors contributed to the article and approved the submitted version.

\section{FUNDING}

Project supported by Clinical Research Project of Tongji Hospital of Tongji University (Grant No. ITJ(ZD)1904), Shanghai Municipal Health Commission to LS (201840217), Clinical Science and Technology Innovation Program of Hospital Development Center to LS (SHDC12018X10) and Shanghai Science and Technology Foundation to LS (19ZR1448600).

\section{SUPPLEMENTARY MATERIAL}

The Supplementary Material for this article can be found online at: https://www.frontiersin.org/articles/10.3389/fendo.2021.531904/ full\#supplementary-material

2. Papatheodorou K, Papanas N, Banach M, Papazoglou D, Edmonds M. Complications of Diabetes 2016. J Diabetes Res (2016) 2016:6989453. doi: $10.1155 / 2016 / 6989453$

3. Janghorbani M, Van Dam RM, Willett WC, Hu FB. Systematic Review of Type 1 and Type 2 Diabetes Mellitus and Risk of Fracture. Am J Epidemiol (2007) 166(5):495-505. doi: 10.1093/aje/kwm106 
4. Rathmann W, Kostev K. Fracture Risk in Patients With Newly Diagnosed Type 2 Diabetes: A Retrospective Database Analysis in Primary Care. J Diabetes its Complications (2015) 29(6):766-70. doi: 10.1016/j.jdiacomp. 2015.05.007

5. Schwartz AV, Vittinghoff E, Bauer DC, Hillier TA, Strotmeyer ES, Ensrud KE, et al. Association of BMD and FRAX Score With Risk of Fracture in Older Adults With Type 2 Diabetes. Jama (2011) 305(21):2184-92. doi: 10.1001/ jama.2011.715

6. Leslie WD, Johansson H, McCloskey EV, Harvey NC, Kanis JA, Hans D. Comparison of Methods for Improving Fracture Risk Assessment in Diabetes: The Manitoba Bmd Registry. J Bone Min Res Off J Am Soc Bone Min Res (2018) 33(11):1923-30. doi: 10.1002/jbmr.3538

7. Napoli N, Chandran M, Pierroz DD, Abrahamsen B, Schwartz AV, Ferrari SL. Mechanisms of Diabetes Mellitus-Induced Bone Fragility. Nat Rev Endocrinol (2017) 13(4):208-19. doi: 10.1038/nrendo.2016.153

8. Johnston SS, Conner C, Aagren M, Ruiz K, Bouchard J. Association Between Hypoglycaemic Events and Fall-Related Fractures in Medicare-covered Patients With Type 2 Diabetes. Diabetes Obes Metab (2012) 14(7):634-43. doi: 10.1111/j.1463-1326.2012.01583.x

9. Vellas B, Fielding R, Bhasin S, Cerreta F, Goodpaster B, Guralnik JM, et al. Sarcopenia Trials in Specific Diseases: Report by the International Conference on Frailty and Sarcopenia Research Task Force. J frailty Aging (2016) 5 (4):194-200. doi: 10.14283/jfa.2016.110

10. Lim Y, Chun S, Lee JH, Baek KH, Lee WK, Yim HW, et al. Association of Bone Mineral Density and Diabetic Retinopathy in Diabetic Subjects: The 20082011 Korea National Health and Nutrition Examination Survey. Osteoporosis Int (2016) 27(7):2249-57. doi: 10.1007/s00198-016-3527-5

11. Schwartz AV, Vittinghoff E, Sellmeyer DE, Feingold KR, de Rekeneire N, Strotmeyer ES, et al. Diabetes-Related Complications, Glycemic Control, and Falls in Older Adults. Diabetes Care (2008) 31(3):391-6. doi: 10.2337/ $\mathrm{dc} 07-1152$

12. Ferrari SL, Abrahamsen B, Napoli N, Akesson K, Chandran M, Eastell R, et al. Diagnosis and Management of Bone Fragility in Diabetes: An Emerging Challenge. Osteoporosis Int (2018) 29(12):2585-96. doi: 10.1007/ s00198-018-4650-2

13. Yamamoto M, Yamauchi M, Sugimoto T. Prevalent Vertebral Fracture is Dominantly Associated With Spinal Microstructural Deterioration Rather Than Bone Mineral Density in Patients With Type 2 Diabetes Mellitus. PloS One (2019) 14(9):e0222571. doi: 10.1371/journal.pone.0222571

14. Adil M, Khan RA, Kalam A, Venkata SK, Kandhare AD, Ghosh P, et al. Effect of Anti-Diabetic Drugs on Bone Metabolism: Evidence From Preclinical and Clinical Studies. Pharmacol Rep PR (2017) 69(6):1328-40. doi: 10.1016/ j.pharep.2017.05.008

15. Tan MC NO, Wong TW, Joseph A, Chan YM, Hejar AR. Definition, Diagnosis and Classification of Diabetes Mellitus and its Complications:Report of a WHO Consultation. Geneva: World Health Organization (1999).

16. Kanis JA, Melton LJ III, Christiansen C, Johnston CC, Khaltaev N. The Diagnosis of Osteoporosis. J Bone Min Res (1994) 9(8):1137-41. doi: 10.1002/ jbmr.5650090802

17. Zeng Q, Li N, Wang Q, Feng J, Sun D, Zhang Q, et al. The Prevalence of Osteoporosis in China, a Nationwide, Multicenter DXA Survey. J Bone Min Res (2019) 34(10):1789-97. doi: 10.1002/jbmr.3757

18. Curry SJ, Krist AH, Owens DK, Barry MJ, Caughey AB, Davidson KW, et al. Screening for Osteoporosis to Prevent Fractures: US Preventive Services Task Force Recommendation Statement. Jama (2018) 319(24):2521-31. doi: 10.1001/jama.2018.7498

19. Wright NC, Looker AC, Saag KG, Curtis JR, Delzell ES, Randall S, et al. The Recent Prevalence of Osteoporosis and Low Bone Mass in the United States Based on Bone Mineral Density At the Femoral Neck or Lumbar Spine. J Bone Min Res (2014) 29(11):2520-6. doi: 10.1002/jbmr.2269

20. Edwards BJ, Brooks ER, Langman CB. Osteoporosis Screening of Postmenopausal Women in the Primary Care Setting: A Case-Based Approach. Gender Med (2004) 1(2):70-85. doi: 10.1016/S1550-8579(04) 80013-5

21. Abrahamsen B, Bonnevie-Nielsen V, Ebbesen EN, Gram J, Beck-Nielsen H. Cytokines and Bone Loss in a 5-Year Longitudinal Study-Hormone Replacement Therapy Suppresses Serum Soluble Interleukin-6 Receptor and Increases interleukin-1-receptor Antagonist: The Danish Osteoporosis
Prevention Study. J Bone Min Res (2000) 15(8):1545-54. doi: 10.1359/ jbmr.2000.15.8.1545

22. Alswat KA. Gender Disparities in Osteoporosis. J Clin Med Res (2017) 9 (5):382-7. doi: 10.14740/jocmr2970w

23. NIH Consensus Development Panel on Osteoporosis Prevention Diagnosis and Therapy. Osteoporosis Prevention, Diagnosis, and Therapy. Jama (2001) 285(6):785-95. doi: 10.1001/jama.285.6.785

24. Jiang X, Good LE, Spinka R, Schnatz PF. Osteoporosis Screening in Postmenopausal Women Aged 50-64 Years: BMI Alone Compared With Current Screening Tools. Maturitas (2016) 83:59-64. doi: 10.1016/ j.maturitas.2015.09.009

25. Kim KC, Shin DH, Lee SY, Im JA, Lee DC. Relation Between Obesity and Bone Mineral Density and Vertebral Fractures in Korean Postmenopausal Women. Yonsei Med J (2010) 51(6):857-63. doi: 10.3349/ymj.2010.51.6.857

26. Neglia C, Argentiero A, Chitano G, Agnello N, Ciccarese R, Vigilanza A, et al. Diabetes and Obesity as Independent Risk Factors for Osteoporosis: Updated Results From the ROIS/EMEROS Registry in a Population of Five Thousand Post-Menopausal Women Living in a Region Characterized by Heavy Environmental Pressure. Int J Environ Res Public Health (2016) 13 (11):1067. doi: 10.3390/ijerph13111067

27. Majumdar SR, Leslie WD, Lix LM, Morin SN, Johansson H, Oden A, et al. Longer Duration of Diabetes Strongly Impacts Fracture Risk Assessment: The Manitoba BMD Cohort. J Clin Endocrinol Metab (2016) 101(11):4489-96. doi: 10.1210/jc.2016-2569

28. Botolin S, Faugere MC, Malluche H, Orth M, Meyer R, McCabe LR. Increased Bone Adiposity and Peroxisomal Proliferator-Activated Receptor-Gamma2 Expression in Type I Diabetic Mice. Endocrinology (2005) 146(8):3622-31. doi: 10.1210/en.2004-1677

29. Wu M, Ai W, Chen L, Zhao S, Liu E. Bradykinin Receptors and EphB2/ EphrinB2 Pathway in Response to High Glucose-Induced Osteoblast Dysfunction and Hyperglycemia-Induced Bone Deterioration in Mice. Int J Mol Med (2016) 37(3):565-74. doi: 10.3892/ijmm.2016.2457

30. Huang KC, Chuang PY, Yang TY, Huang TW, Chang SF. Hyperglycemia Inhibits Osteoblastogenesis of Rat Bone Marrow Stromal Cells Via Activation of the Notch2 Signaling Pathway. Int J Med Sci (2019) 16(5):696-703. doi: 10.7150/ijms. 32707

31. Asadipooya K, Uy EM. Advanced Glycation End Products (Ages), Receptor for AGEs, Diabetes, and Bone: Review of the Literature. J Endocrine Soc (2019) 3(10):1799-818. doi: 10.1210/js.2019-00160

32. An $\mathrm{Y}$, Zhang $\mathrm{H}$, Wang $\mathrm{C}$, Jiao $\mathrm{F}, \mathrm{Xu} \mathrm{H}$, Wang $\mathrm{X}$, et al. Activation of ROS/ Mapks/NF-kb/NLRP3 and Inhibition of Efferocytosis in Osteoclast-Mediated Diabetic Osteoporosis. FASEB J Off Publ Fed Am Soc Exp Biol (2019) 33 (11):12515-27. doi: 10.1096/fj.201802805RR

33. McCarthy AD, Etcheverry SB, Bruzzone L, Cortizo AM. Effects of Advanced Glycation End-Products on the Proliferation and Differentiation of Osteoblast-Like Cells. Mol Cell Biochem (1997) 170(1-2):43-51. doi: 10.1023/A:1006816223292

34. Franke S, Siggelkow H, Wolf G, Hein G. Advanced Glycation Endproducts Influence the mRNA Expression of RAGE, RANKL and Various Osteoblastic Genes in Human Osteoblasts. Arch Physiol Biochem (2007) 113(3):154-61. doi: $10.1080 / 13813450701602523$

35. Tanaka K, Yamaguchi T, Kanazawa I, Sugimoto T. Effects of High Glucose and Advanced Glycation End Products on the Expressions of Sclerostin and RANKL as Well as Apoptosis in Osteocyte-Like MLO-Y4-A2 Cells. Biochem Biophys Res Commun (2015) 461(2):193-9. doi: 10.1016/j.bbrc.2015.02.091

36. Okazaki K, Yamaguchi T, Tanaka K, Notsu M, Ogawa N, Yano S, et al. Advanced Glycation End Products (Ages), But Not High Glucose, Inhibit the Osteoblastic Differentiation of Mouse Stromal ST2 Cells Through the Suppression of Osterix Expression, and Inhibit Cell Growth and Increasing Cell Apoptosis. Calcified Tissue Int (2012) 91(4):286-96. doi: 10.1007/s00223012-9641-2

37. Notsu M, Yamaguchi T, Okazaki K, Tanaka K, Ogawa N, Kanazawa I, et al. Advanced Glycation End Product 3 (AGE3) Suppresses the Mineralization of Mouse Stromal ST2 Cells and Human Mesenchymal Stem Cells by Increasing TGF-beta Expression and Secretion. Endocrinology (2014) 155(7):2402-10. doi: 10.1210/en.2013-1818

38. Neumann T, Lodes S, Kastner B, Franke S, Kiehntopf M, Lehmann T, et al. High Serum Pentosidine But Not esRAGE is Associated With Prevalent 
Fractures in Type 1 Diabetes Independent of Bone Mineral Density and Glycaemic Control. Osteoporosis Int (2014) 25(5):1527-33. doi: 10.1007/ s00198-014-2631-7

39. Zhao Z. Correlation Analysis of Urine Proteins and Inflammatory Cytokines With Osteoporosis in Patients With Diabetic Nephropathy. J Musculoskeletal Neuronal Interact (2018) 18(3):348-53.

40. Jules J, Feng X. In Vitro Investigation of the Roles of the Proinflammatory Cytokines Tumor Necrosis Factor-Alpha and Interleukin-1 in Murine Osteoclastogenesis. Methods Mol Biol (Clifton NJ) (2014) 1155:109-23. doi: 10.1007/978-1-4939-0669-7_10

41. Aguirre L, Napoli N, Waters D, Qualls C, Villareal DT, Armamento-Villareal R. Increasing Adiposity is Associated With Higher Adipokine Levels and Lower Bone Mineral Density in Obese Older Adults. J Clin Endocrinol Metab (2014) 99(9):3290-7. doi: 10.1210/jc.2013-3200

42. Roggia C, Gao Y, Cenci S, Weitzmann MN, Toraldo G, Isaia G, et al. UpRegulation of TNF-Producing T Cells in the Bone Marrow: A Key Mechanism by Which Estrogen Deficiency Induces Bone Loss In Vivo. Proc Natl Acad Sci U S A (2001) 98(24):13960-5. doi: 10.1073/pnas.251534698

43. Holst JJ, Vilsboll T, Deacon CF. The Incretin System and its Role in Type 2 Diabetes Mellitus. Mol Cell Endocrinol (2009) 297(1-2):127-36. doi: 10.1016/ j.mce.2008.08.012

44. Christensen MB, Lund A, Calanna S, Jorgensen NR, Holst JJ, Vilsboll T, et al. Glucose-Dependent Insulinotropic Polypeptide (Gip) Inhibits Bone Resorption Independently of Insulin and Glycemia. J Clin Endocrinol Metab (2018) 103(1):288-94. doi: 10.1210/jc.2017-01949

45. Zhong Q, Itokawa T, Sridhar S, Ding KH, Xie D, Kang B, et al. Effects of GlucoseDependent Insulinotropic Peptide on Osteoclast Function. Am J Physiol Endocrinol Metab (2007) 292(2):E543-8. doi: 10.1152/ajpendo.00364.2006
46. Jeon YK, Bae MJ, Kim JI, Kim JH, Choi SJ, Kwon SK, et al. Expression of Glucagon-Like Peptide 1 Receptor During Osteogenic Differentiation of Adipose-Derived Stem Cells. Endocrinol Metab (Seoul Korea) (2014) 29 (4):567-73. doi: 10.3803/EnM.2014.29.4.567

47. Cordes C, Baum T, Dieckmeyer M, Ruschke S, Diefenbach MN, Hauner H, et al. Mr-Based Assessment of Bone Marrow Fat in Osteoporosis, Diabetes, and Obesity. Front Endocrinol (2016) 7:74. doi: 10.3389/fendo.2016.00074

48. Sheu Y, Amati F, Schwartz AV, Danielson ME, Li X, Boudreau R, et al. Vertebral Bone Marrow Fat, Bone Mineral Density and Diabetes: The Osteoporotic Fractures in Men (MrOS) Study. Bone (2017) 97:299-305. doi: 10.1016/j.bone.2017.02.001

49. Veldhuis-Vlug AG, Rosen CJ. Clinical Implications of Bone Marrow Adiposity. J Internal Med (2018) 283(2):121-39. doi: 10.1111/joim.12718

50. Zhang Z, Ou Y, Sheng Z, Liao E. How to Decide Intervention Thresholds Based on FRAX in Central South Chinese Postmenopausal Women. Endocrine (2014) 45(2):195-7. doi: 10.1007/s12020-013-0076-y

Conflict of Interest: The authors declare that the research was conducted in the absence of any commercial or financial relationships that could be construed as a potential conflict of interest.

Copyright (C) 2021 Wen, Li, Zhang, Liu, Ma, Zhang, Zhang and Song. This is an openaccess article distributed under the terms of the Creative Commons Attribution License (CC BY). The use, distribution or reproduction in other forums is permitted, provided the original author(s) and the copyright owner(s) are credited and that the original publication in this journal is cited, in accordance with accepted academic practice. No use, distribution or reproduction is permitted which does not comply with these terms. 